NBER WORKING PAPER SERIES

DYNAMIC STRATEGIC MONETARY

POLICIES AND COORDINATION

IN INTERDEPENDENT ECONOMIES

\author{
Stephen J. Turnovsky \\ Tamer Basar \\ Vasco d'Orey
}

Working Paper No. 2467
NATIONAL BUREAU OF ECONOMIC RESEARCH 1050 Massachusetts Avenue
Cambridge, MA 02138
December 1987

The research reported here is part of the NBER's research program in International Studies. Any opinions expressed are those of the authors and not those of the National Bureau of Economic Research. 


\title{
Dynamic Strategic Monetary Policies and Coordination in Interdependent Economies
}

\begin{abstract}
This paper develops strategic monetary policies using a standard two-country macro model under flexible exchange rates. The equilibria considered include feedback Nash and feedback Stackelberg, both of which are compared to the Pareto optimal cooperative equilibrium. The optimal policies are obtained as feedback rules in which real money supplies are adjusted to movements in the real exchange rate. The properties of these policies and their welfare implications are analyzed using numerical simulations. The contrast in the present results with those obtained previously for a short-run horizon suggest the importance of both intertemporal and intratemporal tradeoffs in the determination of optimal strategic policies.
\end{abstract}

Stephen J. Turnovsky

Department of Economics

University of Washington

301 Savery Hall

Seattle INA 98195

(206) 543-5955
Tamer Basar

Coordinated Science Lab University of Illinois

401 W. Springfield

Urbana IL 61801
Vasco d'Orey

Department of Economics Universidade Nova de Lisboa

Lisbon

Portugal 
With the increasing interdependence between national economies, there has been a growing interest in problems of strategic policy making and international policy coordination. Research into these issues began with the seminal work of Koichi Hamada (1976), who analyzed issues of monetary policy under Cournot and Stackelberg behavior. His approach was a static one and was based on a fixed exchange rate. His contribution has recently been extended by various authors including Michael Jones (1983), Matthew Canzoneri and Jo Anna Gray (1985), Stephen Turnovsky and Vasco d'Orey (1986).

In this paper we consider the problem of strategic monetary policy making within a dynamic framework. The basic model we employ is a two-country version of the standard Rudiger Dornbusch (1976) model in which the policy makers in the two economies seek to optimize their respective objective functions, taken to be intertemporal quadratic cost functions defined in terms of deviations in output from its natural rate level, on the one hand, and the rate of inflation of the domestic consumer price index (CPI) on the other.

The consideration of these issues within a dynamic context is obviously important. Strategic policies, which are optimal from a short-run viewpoint, may, however, generate intertemporal tradeoffs which over time prove to be adverse. In fact, our results below will suggest this to be the case. Furthermore, the extension to a dynamic framework emphasizes new issues such as the information structure and the corresponding equilibrium concepts. The equilibria we consider are all feedback solutions, in which the policies at each stage make use of current information on key economic variables such as prices and exchange rates, which under our assumptions are observable at that time. Using such information we analyze and compare two noncooperative equilibria, which we consider to be of interest: (i) feedback Nash, and (ii) feedback Stackelberg. ${ }^{1}$

A basic question throughout the recent policy discussion concerns the gains from policy coordination. We address this issue by deriving the Pareto Optimal Cooperative equilibrium, where the two policy makers agree to minimize their aggregate joint welfare costs. This equilibrium is then compared with the two noncooperative equilibria. 
Any strategic policy problem must be generated by some disturbance to an initial equilibrium situation, thereby creating a conflict for the two policy makers. In the present analysis, this is taken to be an initial misalignment in the real exchange rate. In general, this may be the result of a variety of underlying causes. Here, it most naturally reflects past differences in monetary policy, resulting in differential price movements in the two economies and leading to the inherited exchange rate misalignment. The policy problem is therefore to return to equilibrium with a minimum of welfare losses. $^{2}$

The analysis is based on two symmetric economies. This has the advantage of simplifying the feedback rules, with the real money supply in each economy being adjusted to the real exchange rate. Our procedure is to derive analytical expressions for the optimal policies. We then use these analytical expressions to compute values for the policy rules and the welfare gains, using the numerical estimates of the parameters of the model.

This is not the first study to apply dynamic game theory to problems of international macroeconomic policy making. Indeed, the area has recently begun to receive increased attention and recent work by Marcus Miller and Mark Salmon (1985), David Currie and Paul Levine (1985), Gilles Oudiz and Jeffrey Sachs (1985), John Taylor (1985), and Andrew Hughes-Hallett (1984), in particular, should be noted. These contributions can be generally characterized as being variants of the standard Keynesian IS-LM-Phillips Curve framework, and for reasons of analytical complexity employ numerical simulation methods. While this characterization is also true of the present study, it also differs in many key respects. ${ }^{3}$ One of these is in the types of strategic equilibria considered. As noted, we focus on feedback solutions, which are determined using dynamic programming methods and are known to be time consistent. By contrast, authors such as Miller and Salmon, Oudiz and Sachs, and Hughes-Hallett emphasize the contrast between time consistent and time inconsistent solutions.

Much of the literature focuses on the gains from cooperation. In this regard, Miller and Salmon present an example where cooperation may actually lead to welfare losses, a finding also obtained 
previously by Rogoff (1985), although for substantially different reasons. By contrast, this study, like Oudiz and Sachs, and Taylor, finds cooperation to yield welfare gains. These are found to be of the order of around 6-10\%, which are similar in magnitude to those obtained by Taylor, but larger than those suggested by Oudiz and Sachs. Also, in contrast to these latter authors, who find the cooperative solution to be more inflationary than the non-cooperative, we find just the reverse in fact to be the case. This result would appear to be generally consistent with Taylor whose multicountry analysis does not yield a uniform pattern in this respect. Finally, our approach differs from the previous literature in two further aspects. First, to avoid the danger of excessive reliance on specific parameter values, a much more detailed sensitivity analysis is conducted, the result of which is to suggest that our findings are in fact quite robust across parameter sets. Secondly, unlike previous authors, our analysis stresses the contrast between the results obtained in the present dynamic analysis with those obtained previously for the more familiar short-run (one period) model. The differences are shown to be quite striking, highlighting the intertemporal, as well as the intratemporal, tradeoffs involved.

\section{THE THEORETICAL FRAMEWORK}

The analysis of this paper is based on the following two-country macroeconomic model, which is a direct extension of the Dornbusch (1976) framework. It describes two identical countries, each specializing in the production of a distinct good and trading a single common bond. It assumes perfect foresight and is expressed, using discrete time, by the following set of equations

$$
\begin{array}{cc}
Y_{t}=d_{1} Y_{t}^{*}-d_{2}\left[I_{t}-\left(P_{t+1}-P_{t}\right)\right]+d_{3}\left(P_{t}^{*}+E_{t}-P_{t}\right) & \\
Y_{t}^{*}=d_{1} Y_{t}-d_{2}\left[I_{t}^{*}-\left(P_{t+1}^{*}-P_{t}^{*}\right)\right]-d_{3}\left(P_{t}^{*}+E_{t}-P_{t}\right) & \\
M_{t}-P_{t}=e_{1} Y_{t}-e_{2} I_{t} & \\
M_{t}^{*}-P_{t}^{*}=e_{1} Y_{t}^{*}-e_{2} I_{t}^{*} & e_{1}>0, e_{2}>0
\end{array}
$$




$$
\begin{aligned}
& I_{t}=I_{t}^{*}+E_{t+1}-E_{t} \\
& C_{t}=\delta P_{t}+(1-\delta)\left(P_{t}^{*}+E_{t}\right) \\
& C^{*}=\delta P_{t}^{*}+(1-\delta)\left(P_{t}^{*}+E_{t}\right) \\
& P_{t+1}-P_{t}=\gamma Y_{t} \\
& P_{t+1}^{*}-P_{t}^{*}=\gamma Y_{t}^{*} \\
& 1>\delta>1 / 2 \\
& \boldsymbol{\gamma}>0
\end{aligned}
$$

where

$Y=$ real output, in logarithms, measured as a deviation about its natural rate level,

$P=$ price of domestic output, expressed in logarithms,

$C=$ consumer price index, expressed in logarithms,

$E=$ exchange rate (measured in terms of units of foreign currency per unit of domestic currency), measured in logarithms,

$I=$ nominal interest rate, measured in natural units,

$M=$ nominal money supply, expressed in logarithms.

Domestic variables are unstarred; foreign variables are denoted with asterisks. We shall also refer to these as Country 1 and Country 2, respectively.

Equations (1) and (1') describe equilibrium in the two goods markets. Output depends upon the real interest rate, output in the other country, and the relative price. The corresponding effects across the two economies are identical, with relative price influencing demand in exactly offsetting ways. The money market equilibrium conditions in the two economies are standard and are described by (2) and (2'), respectively. The perfect substitutability between domestic and foreign bonds is described by the interest rate parity condition (3). Equations (4) and (4') describe the consumer price index (CPI) in the two economies. They embody the assumption that the proportion of consumption $\delta$ spent on the respective home good is the same in the two economies. ${ }^{5}$ Note that the real interest rate in (1) and (1') and the real money supplies in (2) and (2') are deflated by the output price of their respective economies. Little would be changed, except for additional detail, if the deflators were in terms of 
their respective CPI's. Equations (5) and (5') define the price adjustment in the two economies in terms of Phillips curve relationships, with prices responding with a one-period lag to demand. On the other hand, the assumption of perfect foresight is embodied in the future price level and future exchange rate appearing in the real interest rate in (1), (1'), and the interest rate parity relationship (3).

Equations (1)-(5) describe the structure of the two economies. The policy makers in these economies are assumed to have intertemporal objective functions

$$
\begin{array}{ll}
\sum_{t=1}^{T}\left[a Y_{t}^{2}+(1-a)\left(C_{t+1}-C_{t}\right)^{2}\right] p^{t-1} & \\
\sum_{t=1}^{T}\left[a Y_{t}^{* 2}+(1-a)\left(C_{t+1}^{*}-C_{t}^{2}\right)^{2}\right] p^{t-1} & 0<a<1 \quad 0<\rho<1
\end{array}
$$

which they seek to optimize. That is, each policy maker chooses to minimize an intertemporal cost function. The cost incurred at each point of time is quadratic, defined in terms of deviations in output from their equilibrium, natural rate, level, and the rate of inflation of the domestic cost of living. The relative weights attached to these components of the objective functions are $a$ and $1-a$, respectively. Total cost to be minimized is a discounted sum of the costs incurred at each period, with $\rho$ denoting the discount rate. Equations (1)-(5) may be solved for $Y_{t}, Y_{t}^{*}$, and $E_{t+1}-E_{t}$, as follows

$$
\begin{gathered}
Y_{t}=\phi_{1} m_{t}+\phi_{2} m_{t}^{*}+\phi_{3} s_{t} \\
Y_{t}^{*}=\phi_{2} m_{t}+\phi_{1} m_{t}^{*}-\phi_{3} s_{t} \\
E_{t+1}-E_{t}=-\beta_{1} m_{t}+\beta_{1} m_{t}^{*}+\beta_{3} s_{t}
\end{gathered}
$$

where

$s_{t} \equiv P_{t}^{*}+E_{t}-P_{t}$ denotes the relative price (real exchange rate) at time $t$, $m_{t} \equiv M_{t}-P_{t}, m_{t}^{*} \equiv M_{t}^{*}-P_{t}^{*}$ denote the real stocks of money at home and abroad, at time $t$,

$$
\phi_{1} \equiv \frac{d_{2}}{2},\left[\frac{1}{D}+\frac{1}{D^{\prime}}\right] ; \phi_{2} \equiv \frac{d_{2}}{2}\left[\frac{1}{D}-\frac{1}{D^{\circ}}\right] ; \phi_{3}=\frac{e_{2} d_{3}}{D^{\prime}}
$$




$$
\begin{gathered}
\beta_{1}=\frac{1+d_{1}-d_{2} \gamma}{D^{\prime}} ; \beta_{2}=\frac{2 e_{1} d_{3}}{D^{\prime}} \\
D \equiv e_{2}\left(1-d_{1}-d_{2} \gamma\right)+e_{1} d_{2} ; \quad D^{\prime}=e_{2}\left(1+d_{1}-d_{2} \gamma\right)+e_{1} d_{2}
\end{gathered}
$$

We assume that $1-d_{1}-d_{2} \gamma>0$, implying that the IS curve of the aggregate world economy is downward sloping. It follows that

$$
D^{\prime}>D>0
$$

and hence

$$
\phi_{1}>\phi_{2}>0
$$

Taking the differences of the cost of living equations (4) at two consecutive points in time, and using (5), (5'), and (7a)-(7c), the rates of inflation of the CPI become

$$
\begin{aligned}
& C_{t+1}-C_{t}=\eta_{1} m_{t}+\eta_{2} m_{t}^{*}+\eta_{3} s_{t} \\
& C_{t+1}^{*}-C_{t}^{*}=\eta_{2} m_{t}+\eta_{1} m_{t}^{*}-\eta_{3} s_{t}
\end{aligned}
$$

where

$$
\begin{gathered}
\eta_{1} \equiv \gamma\left[\delta \phi_{1}+(1-\delta) \phi_{2}\right]-\beta_{1}(1-\delta) \\
\eta_{2} \equiv \gamma\left[\delta \phi_{2}+(1-\delta) \phi_{1}\right]+\beta_{1}(1-\delta) \\
\eta_{3} \equiv \gamma \phi_{3}(2 \delta-1)+\beta_{2}(1-\delta)
\end{gathered}
$$

The optimal policy problem confronting each of the policy makers is to choose their respective money supplies to minimize their cost functions (6) and (6') subject to constraints (8a), (8b), (9a), (9b). Given the assumption that prices move gradually at home and abroad, we assume that both $P_{t}$ and $P_{t}^{*}$ are observed at time $t$. Thus it is convenient to treat the monetary control variables as being the real quantities $m, m^{*}$. Secondly, we assume that the current nominal exchange rate $E_{t}$ is observed instantaneously and can therefore be monitored by the monetary authorities. ${ }^{6}$ Thus the relative price, $s_{t}$, is observable to both policy makers at time $t$, and in fact the optimal monetary policies will be obtained as feedback solutions in terms of $s_{t}$. Combining equations (5), (5), and (7c), $s_{t}$ follows the path

$$
s_{t+1}=c s_{t}+b m_{t}-b m_{t}^{*}
$$

where

$$
c \equiv 1+\beta_{2}-2 \gamma \phi_{3}
$$




$$
b \equiv-\left(1+d_{1}\right) / D^{\prime}
$$

In considering equation (9), it should be noted that $m_{t}, m_{t}^{*}$ denote real money stocks, which given that the price levels $P_{t}, P_{t}^{*}$ are constrained to move sluggishly, can be treated as policy variables. With forward looking variables, such as the nominal exchange rate, one normally expects the dynamics of such a system to involve a saddlepoint. This is in fact also the case here, when one makes the usual assumption that the nominal money supplies remain fixed, or follow some exogenous path. In this case to specify the dynamics, one needs to combine (9) with the price adjustment equations (5), (5') together with (7a), (7b). The result of this is the following matrix equation system

$$
\left[\begin{array}{l}
s_{t+1} \\
P_{t+1} \\
P_{t+1}^{*}
\end{array}\right]=\left[\begin{array}{rcr}
c & -b & b \\
\phi_{3} & 1-\gamma \phi_{1} & -\gamma \phi_{2} \\
-\phi_{3} & -\gamma \phi_{2} & 1-\gamma \phi_{1}
\end{array}\right]\left[\begin{array}{l}
s_{t} \\
P_{t} \\
P_{t}^{*}
\end{array}\right]+\left[\begin{array}{cc}
b & -b \\
\gamma \phi_{1} & \gamma \phi_{2} \\
\gamma \phi_{2} & \gamma \phi_{1}
\end{array}\right]\left[\begin{array}{l}
M_{t} \\
M_{t}^{*}
\end{array}\right]
$$

Under plausible conditions, for given $M_{t}, M_{t}^{*}$, this will have two stable and one unstable root, with the real exchange rate jumping (via the nominal rate) to ensure that the system is always following a stable path. ${ }^{7}$ But with endogenous feedback policy, stability can be accomplished through appropriate adjustments in the policy variables. The unstable root may be eliminated from the system, ruling out the need for the exchange rate to undergo endogenous jumps.

In order to see how the strategic problem is generated, suppose that prior to time 1 the two monetary authorities have been allowing their respective nominal money stocks to follow exogenous time paths. From equations (10) we see that the real exchange rate $s_{t+1}$ is generated by

$$
\begin{aligned}
s_{t+1} & =c s_{t}-b\left[P_{t}-P_{t}^{*}\right]+b\left[M_{t}-M_{t}^{*}\right] \\
& =c s_{t}+b\left[\left(M_{t}-P_{t}\right)-\left(M_{t}^{*}-P_{t}\right)\right] \\
& =\left[1-\gamma\left(\phi_{1}-\phi_{2}\right)+c\right] s_{t}+\left[c\left[1-\gamma\left(\phi_{1}-\phi_{2}\right)\right]+2 b \phi_{3} s_{t-1}+b\left[\Delta M_{t}-\Delta M_{t}^{*}\right]\right.
\end{aligned}
$$

Assume that at some distant time in the past, the world economy was in long-run equilibrium with $s=0$. It is then evident from this equation (or more precisely its stable solution) that the 
misalignment in the real exchange rate, which forms the starting point for the present strategic analysis, reflects differential monetary policies in the two economies over the entire prior period and in particular how these manifest themselves in differential real money stocks. These disturbances can be either transitory, lasting just one period; or they can be sustained differences in monetary growth rates. These will simply result in different values of the real exchange rate at time 1 . Even though any stable adjustment path will ensure the ultimate reattainment of the equilibrium exchange rate, the introduction of strategic behavior at some arbitrary point can be viewed as an attempt to accelerate this adjustment process. In a more general model, a misaligned initial exchange rate could also reflect other factors, such as differential fiscal policies or supply shocks to the two economies.

The dynamic optimization problem faced by the two policy makers may be summarized as

$$
\operatorname{Min} J_{T}=\sum_{t=1}^{T}\left[a Y_{t}^{2}+(1-a)\left(C_{t+1}-C_{t}\right)^{2}\right] \rho^{t-1}
$$

and

subject to

$$
\begin{gathered}
Y_{t}=\phi_{1} m_{t}+\phi_{2} m_{t}^{*}+\phi_{3} s_{t} \\
C_{t+1}-C_{t}=\eta_{1} m_{t}+\eta_{2} m_{t}^{*}+\eta_{3} s_{t}
\end{gathered}
$$

where

$$
\begin{gathered}
\text { Min } J_{T}^{*}=\sum_{t=1}^{T}\left[a Y_{t}^{* 2}+(1-a)\left(C_{t+1}^{*}-C_{t}^{*}\right)^{2}\right] p_{t-1} \\
\text { subject to } \begin{array}{c}
Y_{t}^{*}=\phi_{2} m_{t}+\phi_{1} m_{t}^{*}-\phi_{3} s_{t} \\
C_{t+1}^{*}-C_{t}^{*}=\eta_{2} m_{t}+\eta_{1} m_{t}^{*}-\eta_{3} s_{t}
\end{array}
\end{gathered}
$$

and

$$
m_{t}=f_{t}\left(s_{t}\right), m_{t}^{*}=f_{t}^{*}\left(s_{t}^{*}\right)
$$

and the minimizations in (10) and $\left(10^{\prime}\right)$ are performed over the policy rules $f_{t}$ and $f_{t}^{*}$, respectively under different modes of decision making.

\section{DERIVATION OF NONCOOPERATIVE EQUILIBRIA}

Equations (11)-(14) specify a dynamic game, the solution to which will be considered under 
different behavioral assumptions for policy makers in each country. Specifically, we will study the equilibrium solution under the assumption of (i) Cournot-Nash, (ii) Stackelberg behavior on the part of the policy makers.

To begin, we first substitute (12) and (13) into (11) and $\left(12^{\prime}\right),\left(13^{\prime}\right)$ into $\left(11^{\prime}\right)$ enabling us to express each country's objective function in terms of only the state variable, $s_{t}$, and the control varibales of both countries, $m_{t}, m_{t}^{*}$. The resulting expressions are

$$
\begin{aligned}
& J_{T}=\sum_{t=1}^{T}\left[Q_{1} s_{t}^{2}+2 Q_{2} s_{t} m_{t}+2 Q_{3} s_{t} m_{t}^{*}+2 Q_{4} m_{t} m_{t}^{*}+Q_{5} m_{t}^{2}+Q_{6} m_{t}^{* 2}\right] p^{t-1} \\
& J_{T}^{*}=\sum_{t=1}^{T}\left[Q_{1}^{*} s_{t}^{2}+2 Q_{2}^{*} s_{t} m_{t}^{*}+2 Q_{3}^{*} s_{t} m_{t}^{*}+2 Q_{4}^{*} m_{t} m_{t}^{*}+Q_{5}^{*} m_{t}^{* 2}+Q_{6}^{*} m_{t}^{*}\right] p^{t-1}
\end{aligned}
$$

where

$$
\begin{array}{cl}
Q_{1} \equiv a \phi_{3}^{2}+(1-a) \eta_{3}^{2} \equiv Q_{1}^{*} ; & Q_{2} \equiv a \phi_{1} \phi_{3}+(1-a) \eta_{1} \eta_{3} \equiv-Q_{2}^{*} \\
Q_{3} \equiv a \phi_{2} \phi_{3}+(1-a) \eta_{2} \eta_{3} \equiv-Q_{3}^{*} ; & Q_{4} \equiv a \phi_{1} \phi_{2}+(1-a) \eta_{1} \eta_{2} \equiv Q_{4}^{*} \\
Q_{5} \equiv a \phi_{1}^{2}+(1-a) \eta_{1}^{2} \equiv Q_{5}^{*} ; & Q_{6} \equiv a \phi_{2}^{2}+(1-a) \eta_{2}^{2} \equiv Q_{6}^{*}
\end{array}
$$

Together with the evolution equation for the state variable, (14a), and the policy rules, (14b), the expressions for the cost functionals $J_{T}$ and $J_{T}^{*}$, as given by (15), (15'), provide a convenient framework for the application of the available theory on dynamic games to this two-country model. ${ }^{8}$

\section{A. Closed-Loop (Feedback) Nash Equilibrium Solution}

The first type of equilibrium we will be addressing is the noncooperative Nash equilibrium under the so-called feedback information pattern (for both countries) as dictated by (13b). ${ }^{9}$ Using the recursive technique given in Basar and Olsder (1982, Chapter 6), the solution of the dynamic game can be shown to be unique, and linear in the current value of the state, yielding the expressions given below in Proposition II.1. It is also time consistent. ${ }^{10}$

Proposition II.I: For the T-period dynamic game, the feedback Nash equilibrium solution is unique and is given by

$$
m_{t}=f_{t, T}\left(s_{t}\right)=\alpha_{r} s_{t}
$$




$$
\begin{gathered}
m_{t}^{*}=f_{t, T}^{*}\left(s_{t}\right)=\alpha_{\tau}^{*} s_{t} \\
\tau \equiv T-t ; t=1,2, \ldots, T
\end{gathered}
$$

where

$$
\begin{gathered}
\alpha_{\tau}=\frac{q_{2, \tau} q_{5, \tau}^{*}-q_{2, \tau}^{*} q_{4, \tau}^{*}}{q_{4, \tau} q_{4, \tau}^{*}-q_{5, \tau} q_{5, \tau}^{*}} \\
\alpha_{r}^{*}=\frac{q_{2, \tau}^{*} q_{5, \tau}-q_{2, \tau} q_{4, \tau}^{*}}{q_{4, \tau}^{*} q_{4, \tau}-q_{5, \tau}^{*} q_{5, \tau}} \\
q_{1, \tau}=\rho c^{2} \epsilon_{\tau-1}+Q_{1}, \quad q_{1, \tau}^{*}=\rho c^{2} \epsilon_{\tau-1}^{*}+Q_{1}^{*} \\
q_{2, \tau}=\rho c b \epsilon_{\tau-1}+Q_{2}, \quad q_{2, \tau}^{*}=-\rho c b \epsilon_{\tau-1}^{*}+Q_{2}^{*} \\
q_{3, \tau}=-\rho c b \epsilon_{\tau-1}+Q_{3}, \quad q_{3, \tau}^{*}=\rho c b \epsilon_{\tau-1}^{*}+Q_{3}^{*} \\
q_{4, \tau}=-\rho b^{2} \epsilon_{\tau-1}+Q_{4}, \quad q_{4, \tau}^{*}=-\rho b^{2} \epsilon_{\tau-1}^{*}+Q_{4}^{*} \\
q_{5, \tau}=\rho b^{2} \epsilon_{\tau-1}+Q_{5}, \quad q_{5, r}^{*}=\rho b^{2} \epsilon_{\tau-1}^{*}+Q_{5}^{*} \\
q_{6, \tau}=\rho b^{2} \epsilon_{\tau-1}+Q_{6}, \quad q_{6, \tau}^{*}=\rho b^{2} \epsilon_{\tau-1}^{*}+Q_{6}^{*}
\end{gathered}
$$

and

$$
\begin{gathered}
\epsilon_{\tau}=q_{1, \tau}+2 q_{2, \tau} \alpha_{\tau}+2 q_{3, \tau} \alpha_{\tau}^{*}+2 q_{4, \tau} \alpha_{r} \alpha_{\tau}^{*}+q_{5, \tau} \alpha_{r}^{2}+q_{6, \tau} \alpha_{r}^{* 2} \\
\epsilon_{\tau}^{*}=q_{1, \tau}^{*}+2 q_{2, \tau}^{*} \alpha_{\tau}^{*}+2 q_{3, \tau}^{*} \alpha_{\tau}+2 q_{4, \tau}^{*} \alpha_{,} \alpha_{r}^{*}+q_{5, \tau} \alpha_{\tau}^{* 2}+q_{6_{, \tau}}^{*} \alpha_{r}^{2} \\
\tau=0,1,2, \ldots, T-1
\end{gathered}
$$

with the boundary conditions for the $q$ 's and $q^{*}$ 's being

$$
q_{i, 0}=Q_{i}, \quad q_{i, 0}^{*}=Q_{i}^{*} \quad i=1,2, \ldots, 5
$$

The corresponding Nash equilibrium values for $J_{T}$ and $J_{T}^{*}$, denoted by $J_{T, 1}, J_{T, 1}^{*}$, respectively, are

$$
J_{T, 1}=\epsilon_{T-1} s_{1}^{2}, J_{T, 1}^{*}=\epsilon_{T-1}^{*} s_{1}^{2}
$$

Note that the unique Nash equilibrium optimal policy rules, characterized by the two sequences $\left\{\alpha_{r}\right\}$ and $\left\{\alpha_{\uparrow}\right\}$, depend only on $\tau$, the difference between the terminal time $T$ and the current time $t$, and which therefore represents the "time to go." Since the problem is time invariant, this implies that letting $T \rightarrow \infty$ is equivalent to letting $r \rightarrow \infty$, in the determination of the stationary equilibrium policy rules.

The time paths followed by the two economies are obtained by substituting (16) and (17) into (7)(9). A question which our analysis leaves unresolved concerns $s_{1}$, the initial real exchange rate. In 
rational expectations models this is often determined through an initial jump, which takes the economy onto a stable manifold, thereby ensuring convergence. With active stabilization, however, convergence can be attained without such jumps, as long as the system is controllable. This condition is obviously met for the present model and indeed our numerical results below confirm stability for all parameter sets yielding non-degenerate optimization problems. Under these circumstances, the motivation for the initial jump is not apparent. ${ }^{11}$

No violation either to stability, or to the rationality of expectations, is incurred by treating $s_{1}$ as being determined by past monetary policies. Furthermore, other than as a scale factor, the determination of $s_{1}$ is irrelevant to either the nature of the optimal feedback policy rules, or the time profile of the dynamics, which are our main concern. On the other hand, it would be straightforward, and lead to little change if one allowed $s_{1}$ to be determined by some tradeoff of the future costs contained in (20), with some initial adjustment costs. ${ }^{12}$

\section{B. Feedback Stackelberg Solution}

The Nash equilibrium solution considered above is a symmetric equilibrium concept in terms of the roles of the players in the game. Suppose now, that one of the two policy makers (called the leader) has the power to dominate the decision process. Even in a model such as this, where the structures of the two economies are taken to be symmetric, this case is of interest. For example, Country 1 can be taken to be the U.S., say, and Country 2 to be comprised of a large number of small countries, which together make up Europe and collectively are approximately equivalent to the U.S. in

size and structure. Nevertheless, it does not seem unreasonable to assume that the U.S. by consisting of a single decision making unit, is able to be the dominant player. Such an asymmetry in the roles of the players leads to the Stackelberg solution, which admits two different definitions--global and feedback--depending upon whether can enforce his policy over the entire duration of the game or only from one period to another. The latter mode of play, which corresponds to the "Feedback Stackelberg Solution," allows for a recursive derivation and is the equilibrium solution we will adopt. 
In the derivation of the feedback Stackelberg solution, we follow the recursive technique presented in Basar and Geert Olsder (1982, Chapter 7), which is parallel to the derivation of the Nash solution, the only difference being that now at every stage a static Stackelberg game is solved, instead of a Nash game. Taking Country 1 as the leader and Country 2 as the follower, the solution to the T-period dynamic game (which, like the feedback Nash solution, is time consistent) is presented as follows:

Proposition II.2: For the T-period dynamic game, the feedback Stackelberg solution is unique and is given by

$$
\begin{gathered}
m_{t}=f_{t, T}\left(s_{t}\right)=\alpha_{r} s_{t}, \\
m_{t}=f_{t, T}^{*}\left(s_{t}\right)=\alpha_{r}^{*} s_{t}, \\
\tau \equiv T-t ; t=1,2, \ldots, T
\end{gathered}
$$

where

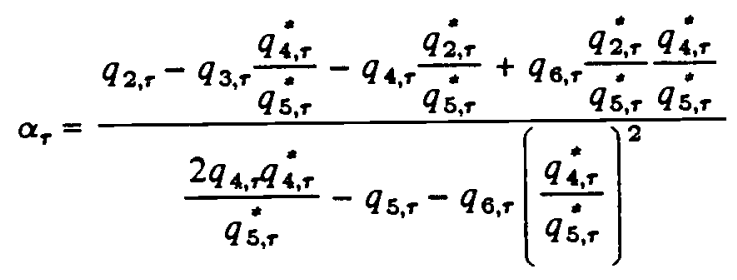

$$
\begin{aligned}
& \alpha_{r}^{*}=-\frac{1}{q_{5, \tau}^{*}}\left[q_{2, \tau}^{*}+q_{4, \tau}^{*} \alpha_{\tau}\right]
\end{aligned}
$$

and $q_{i, \tau}, q_{i, \tau}^{*} i=1,2, \ldots, 5, \epsilon_{\tau}, \epsilon_{\tau}^{*}$ satisfy the same equations as before, i.e., (18), (19), and (19'). The corresponding feedback Stackelberg equilibrium values for $J_{T, 1}$ and $J_{t, 1}^{*}$ are

$$
J_{T, 1}=\epsilon_{T-1} s_{1}^{2}, J_{T, 1}^{*}=\epsilon_{T-1}^{\dot{1}} s_{1}^{2}
$$

\section{COOPERATIVE EQUILIBRIUM}

Suppose now that the two players agree to cooperate by minimizing their joint cost function, $\tilde{J}_{T}=J_{T}+J_{T}^{*}$. By substitution, this can be written as

$$
\operatorname{Min} \widetilde{J}_{T}=\sum_{t=1}^{T}\left[\widetilde{Q}_{1} s_{t}^{2}+2 \widetilde{Q}_{2} s_{t} m_{t}+2 \tilde{Q}_{3} s_{t} m_{t}^{*}+2 \tilde{Q}_{t} m_{t} m_{t}^{*}+\tilde{Q}_{5} m_{t}^{2}+\tilde{Q}_{6} m_{t}^{* 2} b_{t-1}\right.
$$

subject to (13a), (13b), where

$$
\tilde{Q}_{1}=Q_{1}+Q_{1}^{*} ; \quad \tilde{Q}_{4}=Q_{4}+Q_{4}^{*}
$$




$$
\begin{array}{ll}
\widetilde{Q}_{2}=Q_{2}+Q_{3}^{*} ; \quad \widetilde{Q}_{5}=Q_{5}+Q_{6}^{*} \\
\widetilde{Q}_{3}=Q_{3}+Q_{2}^{*} ; \quad \widetilde{Q}_{6}=Q_{6}+Q_{5}^{*}
\end{array}
$$

and $Q_{i}, Q_{i}^{*}$ are defined previously. This is a standard problem in intertemporal optimization, the solution to which is

$$
\begin{aligned}
m_{t} & =\bar{\alpha}_{\tau} s_{t} \\
m_{t}^{*} & =\bar{\alpha}_{\tau}^{*} s_{t}
\end{aligned}
$$

where

$$
\begin{gathered}
\tilde{\alpha}_{\tau}=\frac{\bar{q}_{3, \tau} \widetilde{q}_{4, \tau}-\widetilde{q}_{2, \tau} \widetilde{q}_{6, \tau}}{\widetilde{q}_{5, \tau} \widetilde{q}_{6, \tau}-\bar{q}_{4, \tau}^{2}} \\
\tilde{\alpha}_{\tau}=\frac{\widetilde{q}_{2, \tau} \widetilde{q}_{4, \tau}-\widetilde{q}_{3, \tau} \widetilde{q}_{5, \tau}}{\widetilde{q}_{5, \tau} \widetilde{q}_{6, \tau}-\widetilde{q}_{4, \tau}^{2}}
\end{gathered}
$$

and $\bar{q}_{i, r}$ are determined by equations analogous to (18) and (19). The corresponding cooperative equilibrium value for $\widetilde{J}_{T, 1}$ is

$$
\tilde{J}_{T, 1}=\bar{\epsilon}_{T-1} s_{1}^{2}
$$

with the costs being born equally by the two economies.

\section{STATIONARY EQUILIBRIA}

The solutions discussed in Sections 3 and 4 are based on a finite time horizon. These games are expressed in recursive intensive form, which enables the steady state equilibrium solutions to be derived as the limit of the iterative solutions given above. This procedure is discussed in an expanded version of the paper. Here we only refer briefly to some of the issues.

The stationary solutions are obtained by considering the limits, as $\tau \rightarrow \infty$, of the solutions given in (17), and (18), in the case of the Nash game, and the analogous equations for the other games. Defining the limits

$$
\lim _{r \rightarrow \infty} \alpha_{\tau}=\bar{\alpha}, \quad \lim _{\tau \rightarrow \infty} \alpha_{\tau}^{*}=\bar{\alpha}^{*}
$$

and likewise for $\bar{q}, \vec{q}^{*}, \bar{\epsilon}, \vec{\epsilon}^{*}$, the steady-state policy rules are given by

$$
m_{t}=\bar{\alpha} s_{t}
$$




$$
m_{t}^{*}=\bar{\alpha}^{*} s_{t}
$$

where $\bar{\alpha}, \bar{\alpha}^{*}$, are the solutions to the set of equations obtained by letting $\tau \rightarrow \infty$ in (18), and (19). These constitute highly nonlinear coupled algebraic equations in $\bar{q}, \bar{\epsilon}$, and the recursive procedure we have outlined provides a solution (which is unique) to these coupled equations.

The equilibrium steady-state path, obtained by substituting (26a), (26b) into (9), is given by

$$
s_{t+1}=\left(c+b\left(\bar{\alpha}-\bar{\alpha}^{*}\right)\right) s_{t} \equiv \theta s_{t} \quad t=1,2, \ldots
$$

from which stability follows if and only if

$$
\left|c+b\left(\bar{\alpha}-\bar{\alpha}^{*}\right)\right|<1
$$

The parameter $\theta$ is the steady-state rate of convergence and governs the rate of convergence of all variables in the two economies. Our numerical simulations indicate that this condition is satisfied by our equilibrium solution candidates.

$$
\lim _{T \rightarrow \infty} J_{T, 1}=\bar{\epsilon} S_{1}^{2} \quad \lim _{T \rightarrow \infty} J_{T, 1}^{*}=\vec{\epsilon} s_{1}^{2}
$$

both of which are finite.

\section{NUMERICAL PROCEDURES}

The parameters describing the optimal policies under the various strategic regimes are themselves complex functions of the underlying parameters of the model. Thus apart from revealing the general nature of the optimal policies, it is difficult to gain much insight into the general welfare implications of the different regimes. We therefore use plausible numerical parameter values to evaluate the rules and their welfare differences.

Table 1 indicates a set of base parameter values. These are chosen on the basis of reasonable empirical evidence. The elasticity of the demand for domestic output with respect to the foreign output is $d_{1}=.3$, the semi-elasticity of the demand for output with respect to the real interest rate is $d_{2}=.5$, while the elasticity of the demand for output with respect to the relative price is $d_{3}=1$. The income elasticity of the demand for money is $e_{1}=1$, while the semi-elasticity of money demand with 
respect to the nominal interest rate is .5. The share of domestic consumption is 6 for the two economies; the slopes of their respective Phillips curves are .75. The relative weights given to output stabilization in the objective function is $a=.75$, while the discount rate is $\rho=.9$.

While these values seem reasonable, they are uncertain. In Part B of the table we therefore consider variants of these values, allowing the parameters to range below low values and high values. Note that since $d_{2}, e_{2}$, are semi-elasticities the values of $d_{2}=.5, e_{2}=.5$, correspond to elasticities of around $.03, .05$, respectively. ${ }^{13}$

To consider all combinations of these parameter values would be impractical. Our approach, therefore, is to begin with the base set and introduce one parameter change at a time. Performing these changes in $d_{1}, d_{2}, e_{1}, e_{2}, \delta, \gamma, a$, and $\rho$ gives a total of 28 parameter sets. Parameter Set 1 is the base set; Sets 2-28 are obtained by substituting the corresponding values into the base set.

\section{ALTERNATIVE EQUILIBRIA: BASE PARAMETER SET}

Figures 1-4 illustrate the time paths for the equilibrium solutions corresponding to the base parameter set, described in Table 1. These have been drawn for an initial unit positive shock in the relative price $s$, i.e., for a given initial real depreciation of the currency of Country 1 . The figures are drawn for a time horizon of $T=12$ periods. The three equilibrium solutions are discussed in turn.

\section{A. Feedback Nash}

The time paths for $s_{t}, m_{t}, Y_{t}$, and $\Delta C_{t+1} \equiv\left(C_{t+1}-C_{t}\right)$ under feedback Nash behavior are illustrated in Figures 1, 2a-4a. Given the symmetry of the model, the effects on the two economies are identical (in magnitude), so that the time paths for $m^{*}, Y^{*}, \Delta C^{*}$ are just mirror images of those of $m$, $Y$, and $\Delta C$.

As a benchmark, suppose initially that in response to a unit increase in $s$, there is no response on the part of the two policy makers; that is, $m_{t}=m_{t}{ }^{*}=0$. In effect, the policy makers agree to allow the exchange rate to float freely, so that this is a kind of cooperative equilibrium. In the first instance, the 
positive disturbance in $s$ raises the demand for domestic output and reduces the demand for foreign output. This leads to an increase in domestic output $Y$, matched by an equivalent decrease in foreign output $Y^{*}$. With the real money stocks held constant in both economies, these changes in output will lead to an increase in the domestic interest rate, accompanied by a decrease in the foreign interest rate, the net effect of which is to cause the rate of exchange depreciation of the domestic currency to increase. The increase in domestic output leads to a rise in the inflation rate of domestic output. This together with the increase in the rate of exchange depreciation, causes the rate of inflation of the overall domestic CPI to increase; the opposite occurs abroad.

Next, suppose that as in Turnovsky-d'Orey (1985), each policy maker follows a Nash strategy, using a one-period (static) objective function. In this case, if Country 1 responds to the increase in the relative price by reducing its real money stock, this mitigates the expansion in domestic output, while at the same time raising the domestic interest rate. The opposite effects occur abroad, causing the rate of exchange depreciation of the domestic economy to increase relative to the benchmark case of a perfectly flexible regime. This in turn leads to larger short-run variations in the rate of inflation. The increases in welfare costs associated with this increased price variation more than offset the reduction due to lower income variation, causing the overall costs to increase. Note that this occurs despite the fact that the relative costs attached to output variation are greater. It is a reflection of the quadratic nature of the cost function which penalizes large variations more than proportionately.

Thus for Parameter Set 1, Turnovsky-d'Orey demonstrate that the simple rule of essentially no intervention can dominate other forms of strategic behavior, including Nash and other equilibria. These findings are, however, parameter sensitive, as they note. Moreover, neither the absence of intervention, nor the optimal short-run Nash policy of leaning against the wind is desirable from the viewpoint of long-run welfare maximization. Both strategies are associated with large increases in the rate of exchange depreciation of the domestic currency (larger in the latter case), contributing to large increases in the real exchange rate, which in turn cause the fluctuations in outputs and inflation in the two countries to increase over time. The repetition of either strategy in each period causes the real exchange rate $s$ to follow a divergent time path, with welfare costs ultimately increasing without limit. 
By contrast, the optimal Nash policy, which minimizes the intertemporal cost function, calls for precisely the opposite response, namely an initial real monetary expansion in Country 1, accompanied by a corresponding contraction in Country 2 . These policies cause the level of output in Country 1 to now increase by more than it did in the benchmark situation. By the same token, and by the above reasoning, this causes the rate of exchange depreciation of the domestic currency, and hence the overall rate of domestic inflation, to decrease relative to the benchmark policy. Precisely the opposite effects occur abroad. The reduction in the domestic nominal rate of exchange depreciation, combined with the above movements in domestic and foreign outputs, leads to a reduction in the real exchange rate, $s$. This in turn leads to a mitigation in the fluctuations in outputs and inflation. As a result of implementing the second, and subsequent, stages of the optimization, the real exchange rate follows a convergent path, with steadily declining welfare costs.

For the twelve-period horizon illustrated in Figure 2a, the coefficients of the optimal policy rules $\alpha, \alpha^{*}$, evolve as follows:

$$
\begin{aligned}
& \alpha_{\tau}=-\alpha_{\tau}^{*}=.6847 \quad \tau=11, \ldots, 4 \\
& \alpha_{3}=-\alpha_{3}^{*}=.6856 \\
& \alpha_{2}=-\alpha_{2}^{*}=.6873 \\
& \alpha_{1}=-\alpha_{1}^{*}=.6439 \\
& \alpha_{0}=-\alpha_{0}^{*}=-.9036
\end{aligned}
$$

The interesting point to observe is that in the last period, the policy rule switches sign. This reflects the change in optimal behavior in going from a static to an intertemporal objective function. In fact, the static analysis of Turnovsky-d'Orey is identical to the one-period-to-go solution of the present dynamic analysis. It is also of interest to note that the policy rule converges to its steady state $(\bar{\alpha}=$ $.6837, \bar{\alpha}^{*}=-.6837$ ), within just five periods. Finally, the speed of the adjustment of the economy along the optimal trajectory is given by $\theta=.446$, implying that around $55 \%$ of the adjustment is completed within the first period. ${ }^{14}$

The contrast between the optimal short-run and the optimal long-run policies is striking. We shall restrict our comments to the domestic economy, although analogous reasoning applies abroad. The 
basic cause of the difference stems from the intratemporal tradeoff between output and price variations incorporated in the model, and how this is shifted over time by the chosen policies. Under our assumptions, a depreciation of the domestic real exchange rate generates an increase in the demand for domestic output, leading to an increase in domestic output itself. In effect there is an outward shift in the domestic IS curve, which also leads to an increase in the domestic interest rate, while the increase in domestic output leads to increases in the inflation rates of both the price of domestic output and the domestic CPI. A domestic monetary contraction, as dictated by the short-run optimal strategy, mitigates the short-run fluctuations in output. But, at the same time, this causes the domestic interest rate to increase further, leading to additional increases in the rates of depreciation of both the nominal and real domestic exchange rates, the following period. This in turn leads to a further outward shift in the domestic IS curve and to a deterioration in the next period's tradeoff between output and inflation. For a myopic government, concerned only with the present, this longer-run adverse movement is irrelevant. The short-run contractionary policy, with its dampening effect on output, is clearly desirable.

However, the longer-run effects of the depreciation of the real exchange rate stemming from such a contraction are clearly destabilizing. As $s_{t}$ continues to increase, longer-run fluctuations in real output are generated and variations in the inflation rate are increased. This is not in the interests of a government having a longer-run horizon. Instead, such a government will find it optimal to expand its money supply in the short run. While this will increase the short-run fluctuations in output, it will also stabilize the fluctuations in the real exchange rate, both in the short run and over time. As a consequence of this, a stable long-run adjustment path will be followed. It is interesting to note that this switch in policy occurs within just two periods, the minimum within which the intertemporal (in addition to the intratemporal) tradeoff is introduced. Moreover, the result is robust across all parameter sets.

\section{B. Feedback Stackelberg}


At each stage, the follower's response to the leader's action is given by the relationship

$$
m_{t}^{*}=-\left[q_{2, \tau}^{*} s_{t}+q_{4, \tau}^{*} m_{t}\right] / q_{5, \tau}^{*}
$$

This defines the follower's reaction function, the slope of which is $-q_{4, \tau}^{*} / q_{5, \tau}^{*}$. Being a function of $\tau$, this changes at each stage. Using the base parameter set, Turnovsky and d'Orey show that for the one-period objective, $q_{4}^{*}=.046, q_{5}^{*}=.305$, so that the short-run reaction curve has a negative slope equal to -.15 . This means that the foreign (follower) economy responds to a unit expansion in the domestic (leader) real money supply, with a monetary contraction of .15. Turnovsky-d'Orey characterize the negative slope as being a beggar-thy-neighbor world. ${ }^{15}$ This less than proportionate response by the follower implies that the Stackelberg equilibrium lies at a point on the follower's reaction function, away from the Nash equilibrium, in the direction of the follower's Bliss point. At this equilibrium point, the leader experiences a somewhat larger increase in output, accompanied by a smaller increase in inflation, relative to the Nash equilibrium, while for the follower, the negative fluctuations in both these variables are diminished in magnitude. Furthermore, while the welfare of the leader is higher than at the Nash equilibrium, the gains to the follower are relatively larger.

In the short-run Stackelberg equilibrium of the Turnovsky-d'Orey analysis, the real depreciation of the domestic currency leads to a monetary contraction by the leader. This action, together with the initial real appreciation of the foreign currency, have adverse effects on the level of output in the foreign economy. The foreign monetary authority (the follower) reacts to these negative effects by expanding its money supply, thereby tending to stabilize its level of output. For the same reasons as those given for the feedback Nash solution presented above, these responses lead to an increase in the relative price $s_{t}$, and cause the economy to embark on an unstable time path.

As Figure 2b above, the appropriate initial responses become very different with an intertemporal objective function. Both the leader and the follower should now contract their respective real money stocks, with the contraction by the follower being significantly greater than in the Nash feedback case. The reason for the difference stems from the changed nature of the follower's short-run reaction function. In the initial period, we find $q_{4}^{*}=-4.481, q_{5}^{*}=4.883$, so that the slope of the reaction 
function is now .927 and is positive; this is characterized as being a locomotive world.

The leader knows that if he follows the feedback Nash strategy of expanding the money supply, the follower will tend to respond in a similar fashion. This tends to exacerbate the fluctuations in output in both economies, although the more balanced adjustment means that it is likely to be accompanied by smaller fluctuations in the rate of exchange depreciation (which responds to differential monetary policies), and hence in the rate of inflation of the CPI. Given that the cost function assigns greater weight to output fluctuations than to fluctuations in inflation, this is a nonoptimal situation, particularly for the leader. Accordingly, his strategy is to engage in a monetary contraction, thereby inducing an even greater contraction abroad by the follower. The fact that the contraction is relatively greater abroad causes an appreciation of the domestic currency, which in turn contributes to an appreciation of the real exchange rate, so that $s_{t}$ begins to fall. This pattern of responses continues at each state, thereby enabling the economy to follow a stable path towards equilibrium.

A consequence of the initial worldwide monetary contraction is that the initial stimulating effects of the positive shift in the relative price $s$ on the leader economy is largely eliminated. Indeed, in Period 1, output increases by only .06 units as compared to around .7 for the Nash equilbrium. At the same time, the monetary contraction means that the inflation of $.4 \%$ under Nash becomes a deflation of $.25 \%$ under Stackelberg. In the follower economy, the initial reductions in output and inflation under Nash are even greater under Stackelberg. These comparisons become evident upon examination of Figures $3 a, 3 b$ and $4 a, 4 b$.

Perhaps the most interesting feature of these results is the contrast in the welfares of the leader and follower between the single period and the multiperiod time horizon. We have already noted that for a one-period horizon, the follower is better off than the leader, with both being better off than under Nash. Now we see that over time, the leader improves his welfare vastly, though at the expense of the follower. The welfare costs under Nash to both are .759. Under feedback Stackelberg, however, the leader's costs are reduced to .020 , making him much better off, while for the follower they rise to 
2.758 , resulting in a considerable loss in welfare.

The key to the difference between the short-run and long-run welfare costs is the switch in the follower's reaction function, which occurs over time. As noted, the optimal one-period policies, involving a combination of monetary contraction in the domestic economy and a monetary expansion abroad, destabilize the real exchange rate, affecting both countries adversely over time. To a myopic policy maker this is of no concern. But to a far-sighted policy maker the long-run instability becomes important. The follower knows this and realizes that at each point of time it is up to him to respond in such a way to the leader's actions, to ensure that the relative price follows a stable path. To do this he responds to the real appreciation in his currency with a monetary contraction, at the same time trying to match more closely the qualitative response of the leader. The reason for this is that since $s_{t}$ depends critically upon the difference in the real money stocks, $\left(m_{t}-m_{t}\right)$, minimizing this difference will tend to reduce the instability in $s_{t}$. Thus he will tend to contract when the leader contracts, and vice versa.

For his part, the leader knows the follower's response. But he also knows that the monetary contraction undertaken by the follower in response to his own actions will tend to have an adverse effect on his economy, and he therefore compensates by contracting less. In forcing the follower to respond at each stage to ensure that the relative price is stabilized, the leader is able to exploit his leadership more effectively over time. Basically he can act in his own self interests and is able to impose most of the burden of adjustment on the follower, forcing him to bear the bulk of the adjustment costs. This reversal of the relative welfares occurs even within a two-period horizon, although the differences increase with the length of the time horizon.

This finding raises serious questions of conflict in a multiperiod horizon. Obviously, in this situation neither country will agree to be the follower, raising serious doubts about the viability of the Stackelberg regime, unless there is some other mechanism whereby leadership is determined and enforced.

Finally, the convergence properties of the base parameter set can be summarized. For the 12- 
period horizon illustrated in Figures 2 the coefficients of the policy rules $\alpha_{n} \alpha_{\tau}^{*}$, evolve as follows

$$
\begin{aligned}
& \alpha_{t}=-.3717, \quad \alpha_{\tau}^{*}=-.1891, \quad \tau=11, \ldots, 5 \\
& \alpha_{4}=-.3718, \quad \alpha_{4}^{*}=-.1890 \\
& \alpha_{3}=-.3716, \quad \alpha_{3}^{*}=-.1881 \\
& \alpha_{2}=-.3493, \quad \alpha_{2}^{*}=-.1778 \\
& \alpha_{1}=-.1004, \quad \alpha_{1}^{*}=-.1130 \\
& \alpha_{0}=-.7767, \quad \alpha_{0}^{*}=.8843
\end{aligned}
$$

In this case, the convergence of the policy rule to its steady-state form takes 5 periods. Note again the big jump in the size of the coefficients, between the second to last and last period. While the leader should always adopt a leaning against the wind policy, the response of the follower changes qualitatively during these two periods. The speed of the adjustment of the economy, as described by $\theta$, is .247 , implying that $75 \%$ of the adjustment occurs within one period. This is considerably faster than for the feedback Nash equilibrium.

\section{Cooperative Equilibrium}

Under noncooperative Nash behavior, the monetary authorities in both countries ignore the fact that their own policy responses to the initial disturbance in the real exchange rate have stabilizing effects abroad. For example, the monetary expansion in Country 1 causes both output and CPI inflation abroad to rise, thereby reducing the falls in these quantities abroad resulting from the combined effects of the initial disturbance together with the Nash response of the foreign monetary authority. The opposite applies with respect to Country 2. By taking these externalities into account, the cooperative equilibrium calls for a larger initial monetary expansion in Country 1, accompanied by an equivalently larger contraction in Country 2, relative to the Nash equilibrium. This exacerbates the short-run movements in output in the two economies, while reducing the relative movements in the interest rates. The rate of exchange depreciation of the domestic currency is reduced further (relative to Nash), thereby generating a smaller increase in the domestic rate of inflation. Again, precisely the opposite reactions occur abroad. The increased interventions by the two monetary 
authorities causes a substantial drop in the real exchange rate in the next period, which in turn causes reductions in domestic output and inflation. In fact, the rate of convergence of the cooperative equilibrium is so rapid, that even though output fluctuations are increased initially (relative to Nash), by the second period the relative price has been reduced to such a degree to cause the fluctuations in both output and inflation to be less than in the Nash equilibrium.

For the 12-period horizon, the coefficients of the optimal policy rules $\alpha_{n} \alpha_{r}^{*}$, follow

$$
\begin{aligned}
& \alpha_{\tau}=-\alpha_{\tau}^{*}=.7859 \quad \tau=11, \ldots, 3 \\
& \alpha_{2}=-\alpha_{2}^{*}=.7847 \\
& \alpha_{1}=-\alpha_{1}^{*}=.7433 \\
& \alpha_{0}=-\alpha_{0}^{*}=-.1410
\end{aligned}
$$

As in the other cases, the policy rule switches sign in the last period. The convergence of the control law to its steady state rule is even faster than before, occurring within just three periods. Also, as noted, the speed of adjustment of the system along the optimal trajectory is extremely fast, with around $82 \%$ of the adjustment occurring within the first period.

\section{Overview}

These results show that, at least in the case of Parameter Set 1, all three types of equilibria suggest a sharp contrast between optimal policy with a single-period objective and optimal policy within a dynamic objective function. Basically, the static analysis called for a monetary contraction for Country 1 (experiencing the positive shock in $s$ ), accompanied by an equivalent monetary expansion in Country 2. These responses tend to reduce output fluctuations, while increasing fluctuations in inflation. Given the relative weights on these in the objective function, this is desirable for a oneperiod horizon. However, it is not optimal over the longer run. Such policies generate increasing fluctuations in the relative price, with increasing welfare costs in the future. These can be avoided by adopting policies which generate more variation in output and less variation in inflation.

Finally, we recall that Figures $1-4$ have been drawn for 12 periods. This means that in the last 
period, the paths may begin to diverge, due to the myopic form of the policy rule in that period. Since, after 11 periods of optimal dynamic control, $s$ is by then small, such upturns may be imperceptible. ${ }^{16}$ The time paths for the infinite horizon case are similar, except that the values of $\alpha$, $\alpha$. are the same (at their steady state values) for all periods.

\section{SENSITIVITY ANALYSIS}

In order to determine the robustness of these results, we have recomputed the solutions across the 28 parameter sets discussed in Table 1. The last of these (Set 28 ) is simply the one-period horizon considered by Turnovsky and d'Orey (1986), which corresponds to a discount rate of $\rho=0 .{ }^{17}$ We consider the following three aspects summarizing the equilibria:

(i) The steady state policy rules, $\bar{\alpha}, \bar{\alpha}^{*}$;

(ii) The steady state rate of convergence $\theta$;

(iii) The steady state welfare costs.

\section{A. Steady State Policy Rules}

In virtually all cases, the Nash solution calls for leaning with the wind. Country 1 should expand its (real) money supply in response to the real depreciation of its currency; Country 2 should contract in response to the real appreciation of its currency. By contrast, the Stackelberg leader should almost always lean against the wind, while the follower should always do so with the exception of Set 25 ( $a=$ 1), when the policy game degenerates. ${ }^{18}$ Finally, except in polar cases, the cooperative equilibrium requires more intensive intervention than does the feedback Nash.

\section{B. Steady State Rate of Convergence}

For all but Parameter Sets 10,21, 25, and 28, all optimal paths converge. Parameter Set 28 is the static case, which for reasons discussed at length always leads to divergence. Parameter Sets 21 and 25 are the degenerate extremes, when the targets are always attained perfectly in each period. In this 
case, the divergence of $s_{t}$ is irrelevant. It can always be accommodated by increasing adjustments in the controls $m_{t}, m_{t}^{*}$. The only genuine dynamic gane in which divergence occurs is Set 10 , with $d_{2}=$ 10. This value violates the condition for a downward sloping IS curve and hence instability is not so surprising.

With the exception of the extreme Set 7, for all other sets with $a=.75$, the values of $\theta$ under Nash, Stackelberg, and cooperative behavior, $\theta_{N}, \theta_{S}$, and $\theta_{C}$, respectively, satisfy

$$
\theta_{C}<\theta_{S}<\theta_{N}
$$

implying a clear ranking in the rates of convergence; the cooperative equilibrium is faster than Stackelberg, which in turn is faster than Nash. ${ }^{19}$

\section{Steady State Welfare Costs and the Gains from Cooperation}

The pattern of welfare costs is also remarkably stable and gives rise to a clear ranking among the equilibria. With the exception of the degenerate cases (Sets 21, 25) and the static case (Set 28), the ranking of the different solutions obtained for the base parameter set extends to all other cases. The Stackelberg leadership is the best, while being a Stackelberg follower is the worst equilibrium. In between these extremes we find that the cooperative equilibrium dominates Nash. The welfare costs to the Stackelberg leader are remarkably stable across parameter sets and take him close to his Bliss point (zero costs). By contrast, the Stackelberg follower does extremely poorly, questioning the viability of this regime, relative to the alternatives. ${ }^{20}$

Allowing for compensation, the Nash equilibrium is the preferred noncooperative equilibrium from an overall welfare viewpoint. However, for the base parameter set it still yields welfare losses which are approximately $8 \%$ greater than those for the cooperative equilibrium. The gains from cooperation are generally of this order of magnitude, and are mildly parameter sensitive in ways we will note. Overall, the robustness of these results for the dynamic game are in sharp contrast to the rankings obtained by Turnovsky-d'Orey for the static game, which for the same parameter sets were found to be extremely parameter sensitive. 


\section{CONCLUSIONS}

In this paper we have developed dynamic strategic monetary policies using a standard two-country macro model under flexible exchange rates. Two types of noncooperative equilibria have been considered, namely feedback Nash and feedback Stackelberg. In addition, these have been compared to the Pareto optimal cooperative equilibrium.

The optimal policies have been obtained as feedback rules in which the real money supplies in the respective ecomomies are adjusted to movements in the real exchange rate. Even for a simple model such as this, the derivation of the optimal policies is highly complex, particularly in the limiting case of an infinite time horizon. For this reason, much of our work has proceeded numerically. In carrying out our simulations, we have compared the results obtained from the present dynamic analysis with those obtained previously for the same simulation sets, but using a single period time horizon.

Many of the specific conclusions of our analysis have been noted previously. At this point, several general conclusions are worth highlighting. First, the optimal policies were found to yield convergence for all three equilibria, in the case of virtually all parameter sets. A clear ranking in the rate of convergence was obtained, cooperative behavior yields the fastest convergence, followed by the feedback Stackelberg, with feedback Nash being the slowest.

The results indicate a sharp contrast in both the optimal policies and welfare between the previous results obtained for the short-run time horizon and the present results for the long run, thereby suggesting the importance of intertemporal and intratemporal tradeoffs. As far as welfare is concerned, while in the short run the ranking of the equilibria is highly parameter sensitive, in the long run the rankings are remarkably robust across parameter sets. Specifically, in the long run we find among the noncooperative equilibria, the Stackelberg leader to be the preferred equilibrium, followed by feedback Nash, and Stackelberg follower. The superiorirty of the Stackelberg leader suggests that it takes time for him to be able to exploit his position. The welfare gains from cooperation over Nash are typically of the order of 6-10\%. Although these are modest, they are 
certainly not negligible. ${ }^{21}$

While these results are suggestive and appearing promising, we should note at least two important limitations of our analysis. First, it is based on two symmetric economies, and while this is an obvious natural starting point, it clearly needs to be relaxed. Secondly, the model itself is simple in terms of minimizing the order of the dynamics; extensions in the direction of generating a richer model structure are also desirable, before the results obtained can be maintained with confidence. 
Table 1

Parameter Valuesal

A. Base Set (Par. Set 1)

$$
\begin{array}{r}
d_{1}=.3, d_{2}=.5, d_{3}=1, e_{1}=1.0, e_{2}=.5 \\
\delta=.6, \gamma=.75, a=.75, \rho=.9
\end{array}
$$

B. Variants (Par. Sets 2-28)

$$
\begin{aligned}
& d_{1}: 0, .2, .4, .6, .8 \\
& d_{2}: .01, .25,1.0,10 \\
& e_{1}=0,0.5 \\
& e_{2}=.1,1.0,10 \\
& \delta=.5, .75, .99 \\
& \gamma=.5, .1 \\
& a=0, .2, .4, .6,1 \\
& \rho=.8,1.0 \text { (static) }
\end{aligned}
$$

a/ Since $\mathrm{d}_{3}$ appears as a scale variable applied to $\mathrm{s}$, the results are insensitive to changes in $d_{3}$ (except for a scale factor). We therefore do not consider changes in $d_{3}$, but instead have maintained $d_{3}=1$ throughout. 


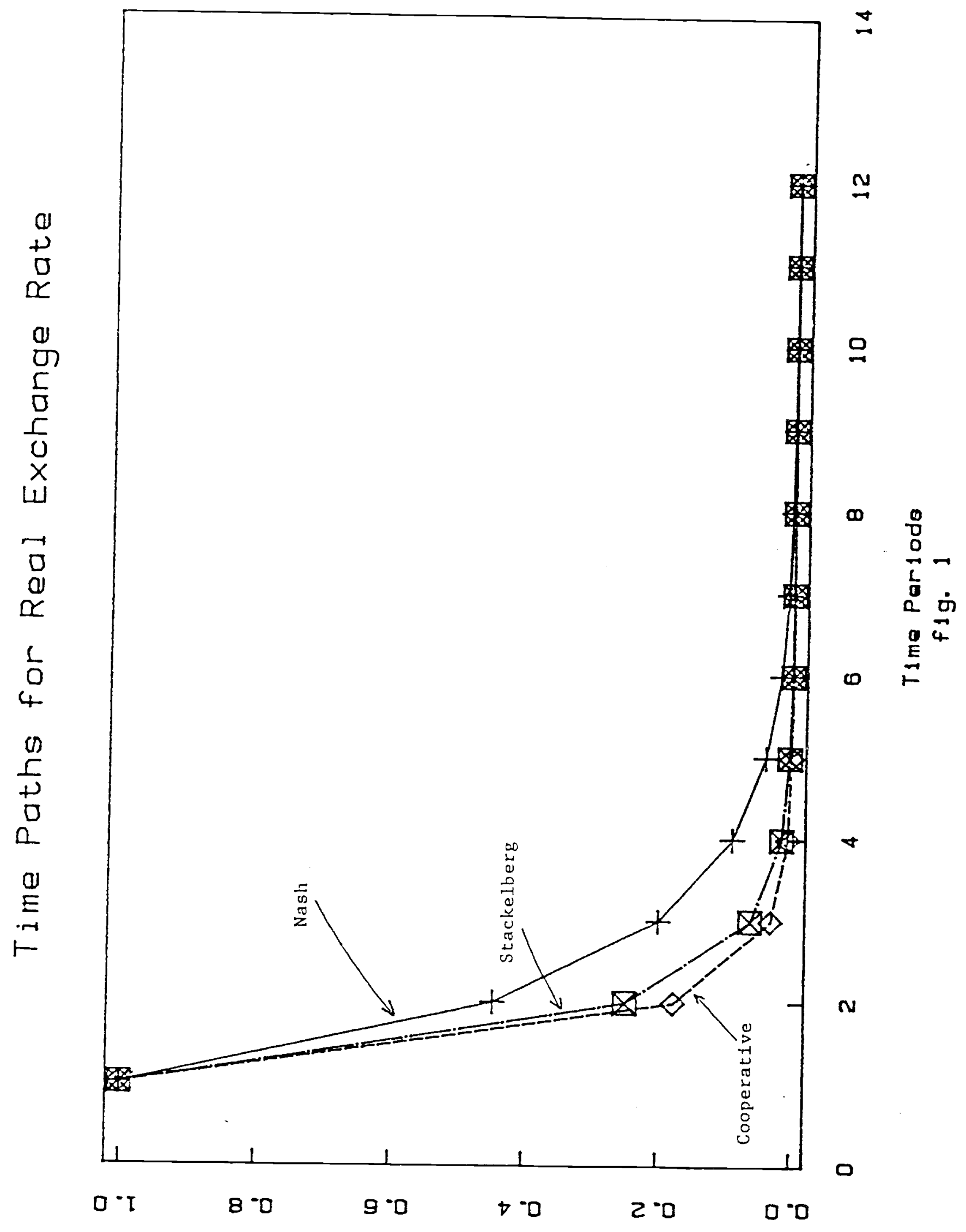




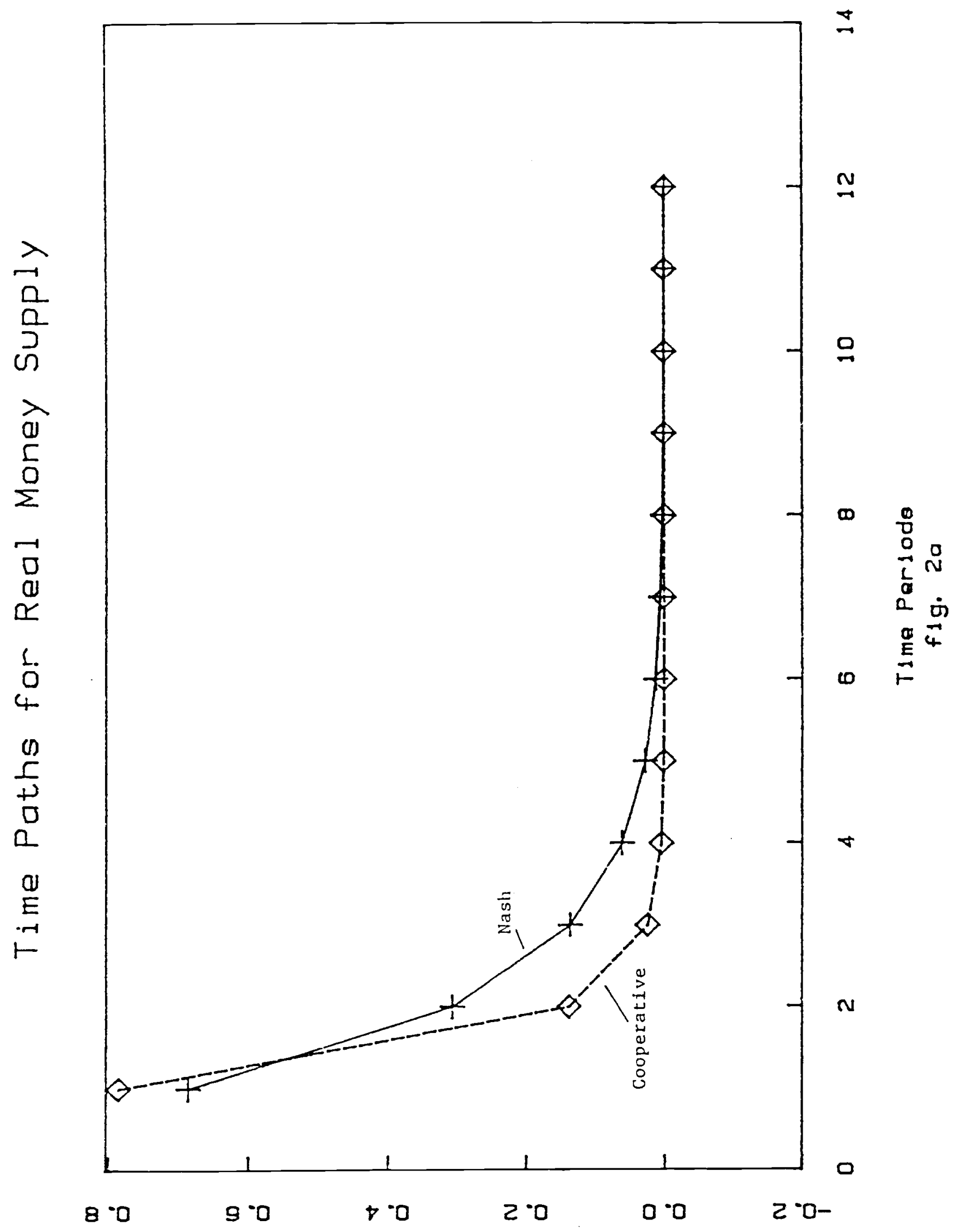




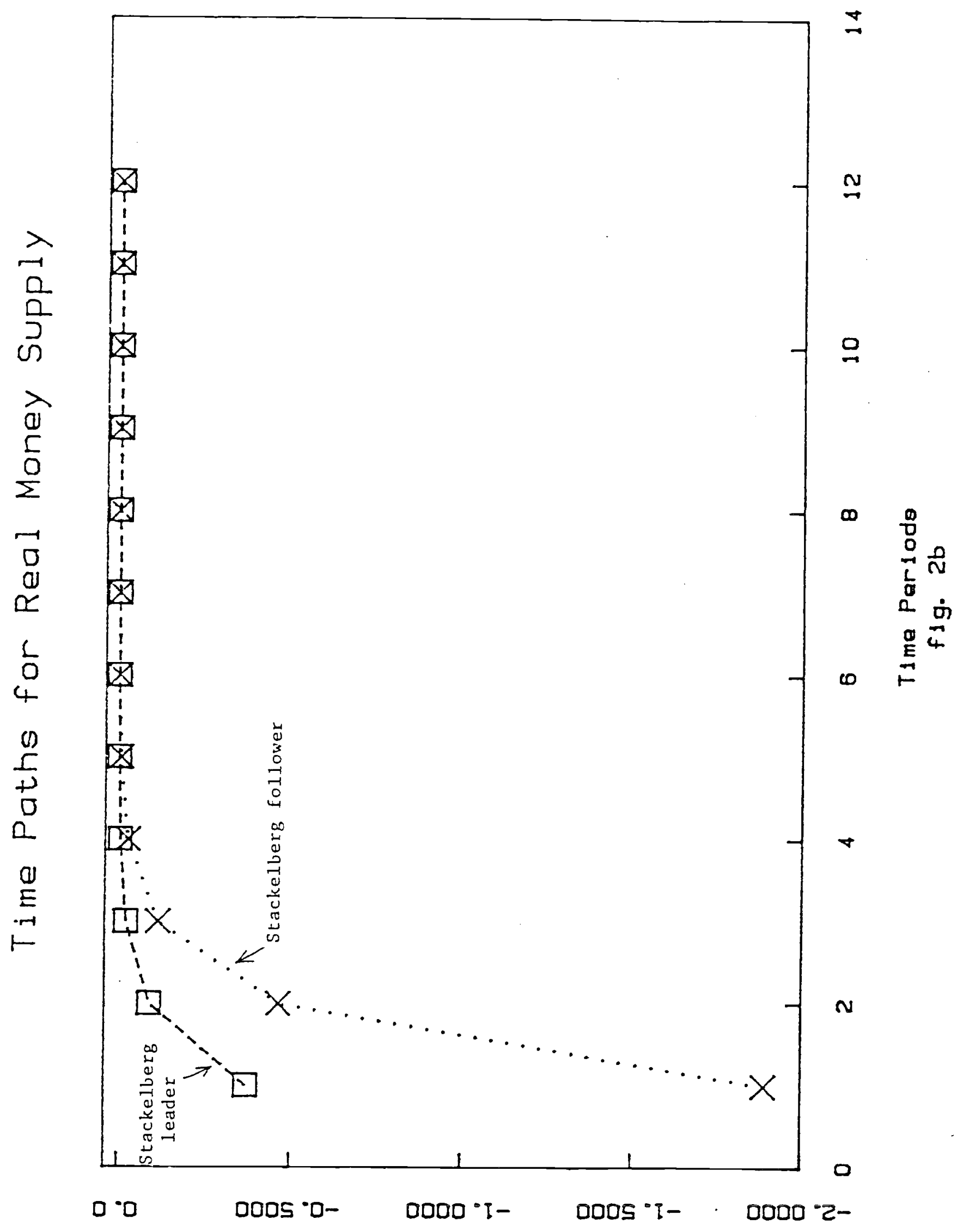




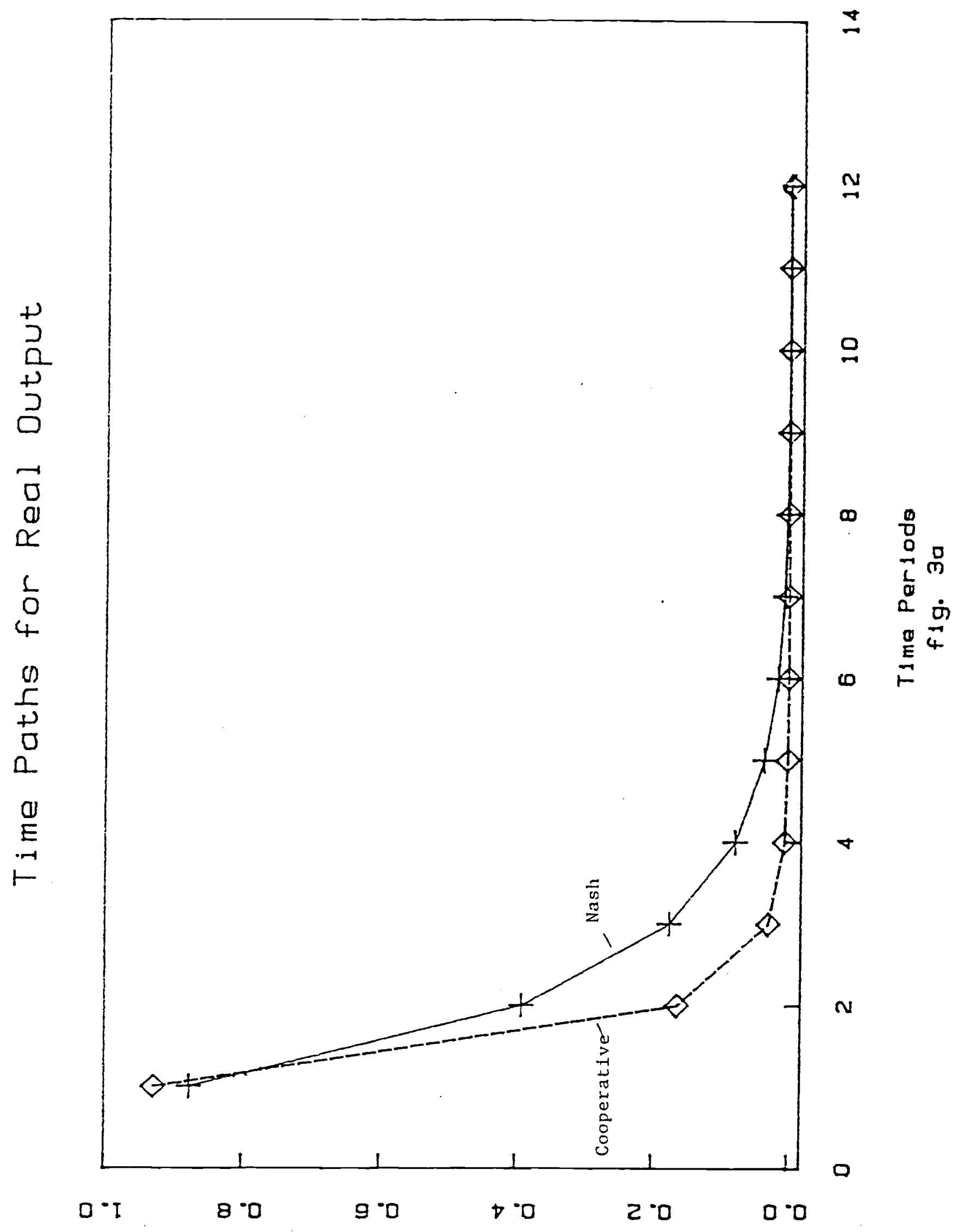




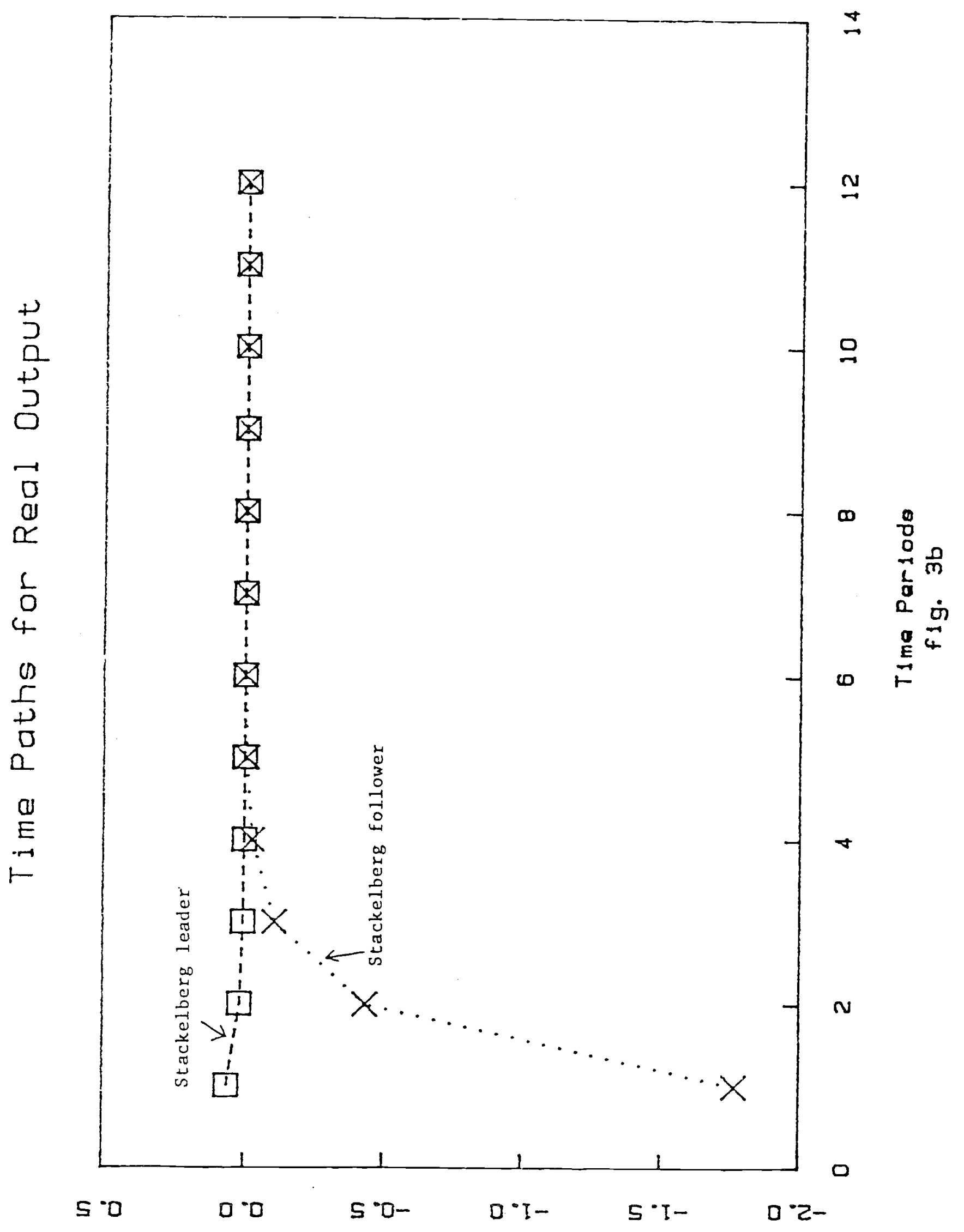




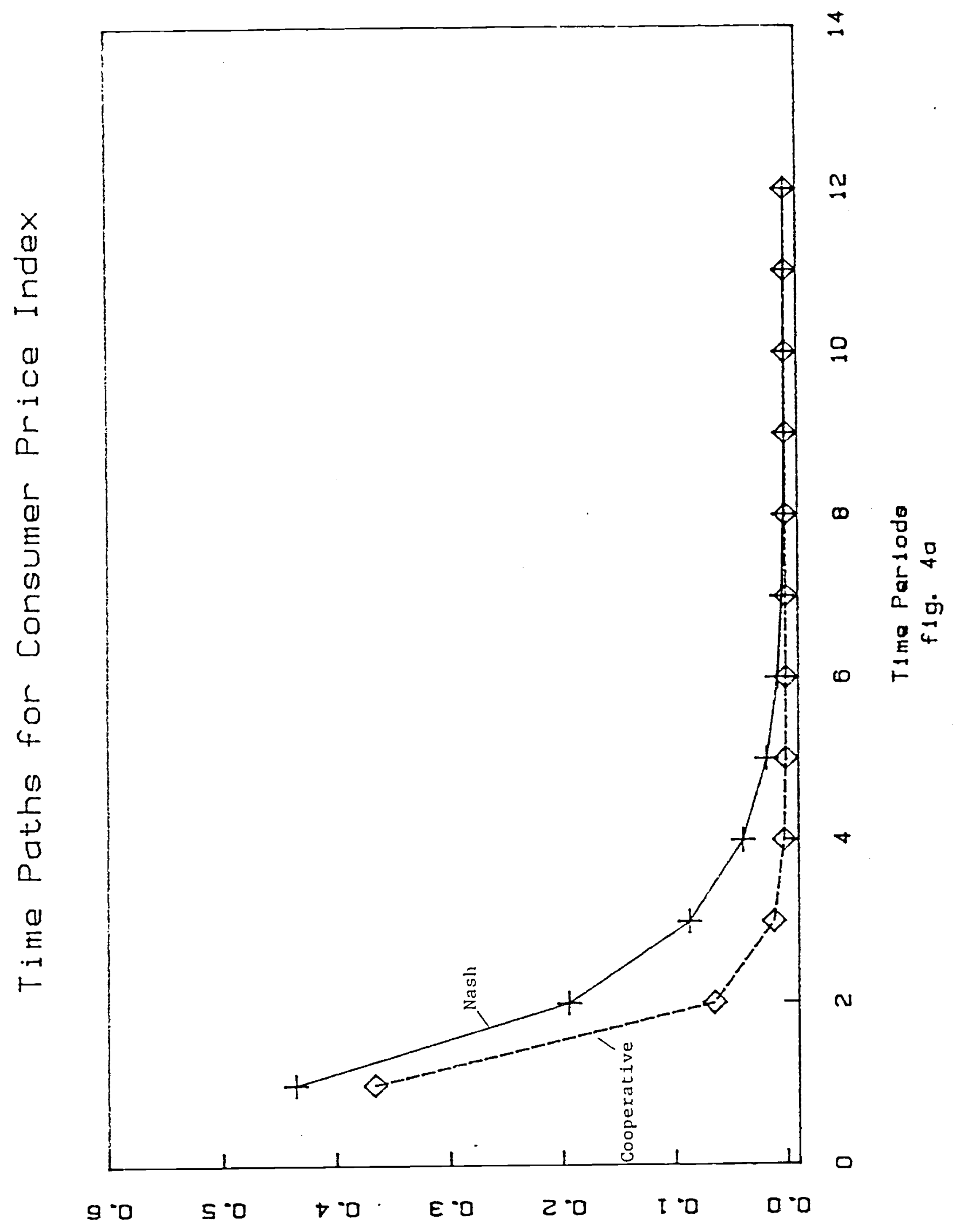




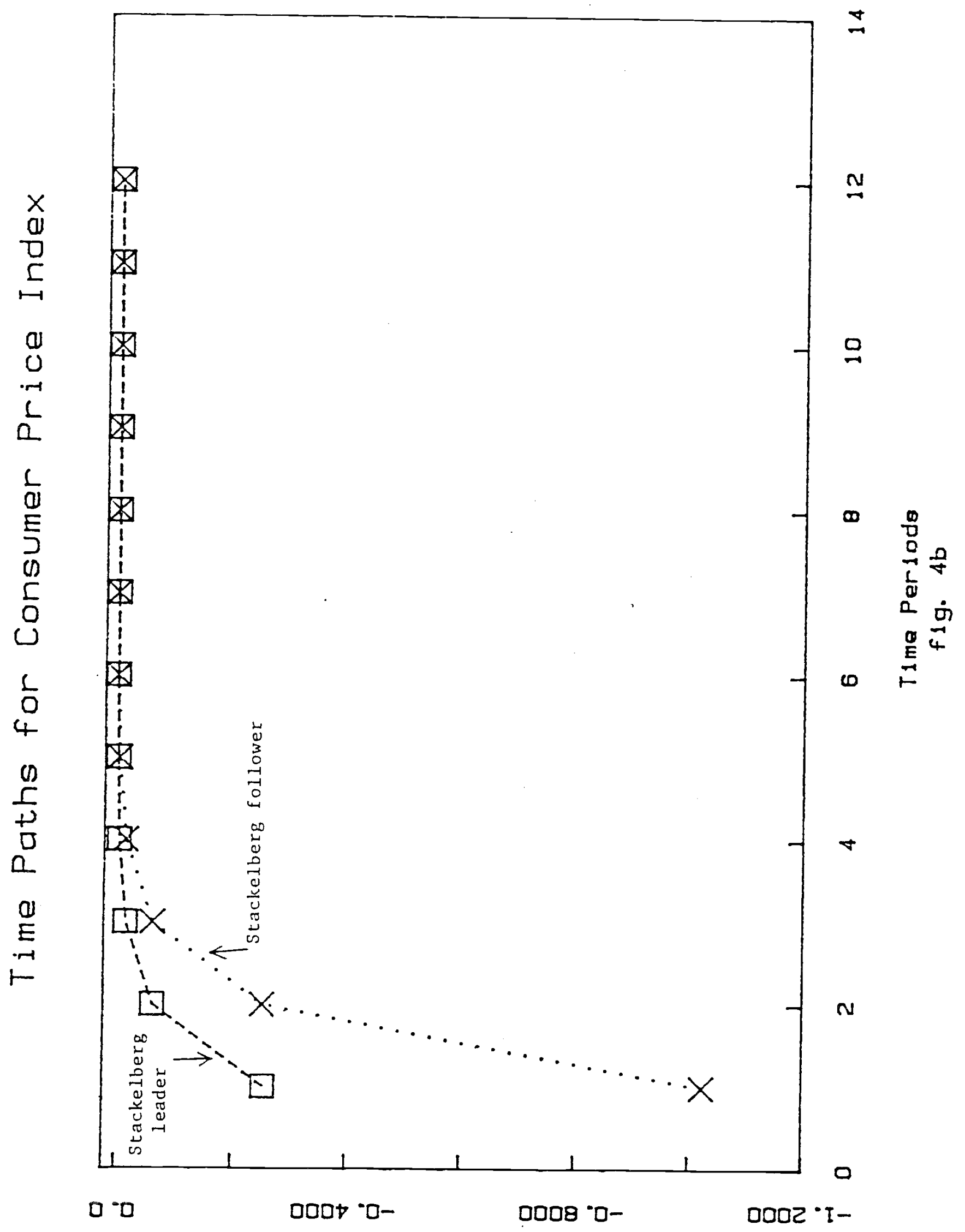


* University of Washington, Seattle and National Bureau of Economic Research; University of Illinois at Urbana-Champaign; Universidade Nova de Lisboa, respectively. Previous versions of this paper were presented at the SEDC Conference held at Imperial College, London, June 1985, the Summer Workshop, held at the University of Warwick, Coventry, 1985, and the ASSA meetings in New York, December 1985. The comments of a referee and a Co-Editor are gratefully acknowledged. This research was supported in part by Grant No. SES-8409886 from the National Science Foundation.

1. In an expanded version of this paper, the feedback Consistent Conjectural Variations (CCV) equilibrium is also considered; see Chaim Ferschtman and Kamien (1985), Tamer Basar (1985). This is a new equilibrium concept in dynamic game theory and is a generalization of the static $\mathrm{CCV}$ equilibrium concept introduced by Timothy Bresnahan (1981), Martin Perry (1982); and Morton Kamien and Nancy Schwartz (1983). A recent paper by Andrew Hughes Hallett (1984) considers arbitrary, but not consistent, conjectural variations in a dynamic policy game framework. Unfortunately, space limitations preclude a detailed discussion of this equilibrium. But some of our results are noted in footnotes at appropriate places.

2. Viewed in this way, the problem may be regarded as being a strategic analogue to the problem of the optimal reduction of inflation originally considered by Phelps (1967) and studied by several authors since.

3. While these papers belong to the same generic class, they differ in terms of their technical details. For example, Miller and Salmon use continuous time, with the interest rate being the policy variable. Oudiz and Sachs introduce more sluggish wage behavior, the result of which is that the optimal monetary rule depends upon a greater set of lagged variables. Currie and Levine have a stochastic model, but consider a set of simple, but not fully optimal, monetary feedback rules, while Taylor assumes staggered wages and prices. Finally, several of the authors consider open-loop, as well as feedback 
rules. We maintain the usual assumption that residents of one country do not hold the currency of the other country.

4. This assumption of the instantaneous observability of the exchange rate is the standard one in the current exchange market intervention literature.

5. For the analysis of exogenous policy shocks in such a model, see Turnovsky (1986).

6. All equilibrium concepts that we will be considering in the following sections do indeed satisfy this property, as will be elucidated later.

7. The time consistency is a consequence of the fact that the solutions are based on feedback rules, which are determined by using dynamic programming methods.

8. In the one-period game, this equilibrium reduces to the usual Cournot equilibrium.

9. The details of the proofs are contained in a longer version of this paper; see Basar, Turnovsky and d'Orey (1985).

10. In effect we have the familiar indeterminacy problem arising from having "too many" stable roots. Using a higher dimension system, Currie and Levine (1985) handle the issue of jumps by invoking the notion of controllability and considering solutions which have the saddlepoint property. Our procedure is the one-dimension analogue of this.

11. An example of this for optimal monetary policy in a s small open economy is given by Stemp and Turnovsky (forthcoming).

12. These statements are based on values of $I=.10, \dot{P}=.04$. Larger values are considered in the sensitivity analysis.

13. The initial shock in the relative price can be thought of as being generated by a transitory disturbance in the previous period.

14. The feedback CCV results are generally similar to the Feedback Nash. The main difference is that since both policy makers are aware of the other's actions, each 
moderates his own adjustment relative to Nash. For parameter set $1, \theta=.789$, implying a substantially slower rate of adjustment.

15. Note that this term is being used in a somewhat different way from its conventional usage. More commonly, a beggar-thy-neighbor world is one in which an expansionary policy in one country causes a contraction (in activity) abroad. Here we are using the term to characterize the interdependence between the adjustments in the policy instruments in the two economies, which in turn involves the slopes of the reaction functions. The same results apply to our usage of the term "locomotive" introduced below.

16. In the case of the CCV solution, however, the upturn is in fact quite marked.

17. For almost all parameter sets the slowest rate of adjustment is achieved under feedback $\mathrm{CCV}$ equilibrium. The reason is that since each policy maker takes account of his rival's actions, this induces caution and gives rise to a more gradual adjustment.

18. The CCV equilibrium always leads to higher welfare costs than Nash. This reflects the fact that $\mathrm{CCV}$ is associated with slower adjustment, thereby contributing to larger intertemporal welfare costs.

19. These numerical estimates of the gains from cooperation are similar in magnitude to those obtained by Taylor (1985). 


\section{REFERENCES}

Basar, T., "A Tutorial on Dynamic and Differential Games," presented at the 7th Annual Conference on Economic Dynamics and Control, London, June 1985.

Basar, T., and G. J. Olsder, Dynamic Noncooperative Game Theory, N.Y., Academic Press, 1983.

Basar, T., S. J. Turnovsky, and V. d'Orey, "Optimal Strategic Monetary Policies in Dynamic Interdependent Economies," presented at the 7th Annual Conference on Economic Dynamics and Control, London, June 1985.

Bresnahan, T. F., "Duopoly Models with Consistent Conjectures," American Economic Review, December 1981, 71, 934-945.

Canzoneri, M. and J. A. Gray, "Monetary Policy Design in an Interdependent World," in W. H. Buiter and R. C. Marston (eds.), International Economic Policy Coordination, Cambridge, U.K., Cambridge University Press, 1985.

Dornbusch, R. "Expectations and Exchange Rate Dynamics," Journal of Political Economy, December 1976, 84, 1161-1176.

Ferschtman, C. and M. I. Kamien, "Conjectural Equilibrium and Strategy Spaces in Differential Games," in Optimal Control Theory and Economic Analysis 2, G. Feichtinger, ed., Amsterdam, North-Holland, 1985.

Hamada, K., "A Strategic Analysis of Monetary Interdependence," Journal of Political Economy, August 1976, 84, 677-700.

Hughes-Hallett, A. J., "Non-Cooperative Strategies for Dynamic Policy Games and the Problem of Time Inconsistency," Oxford Economic Papers, November 1984, 36, 381-399.

Jones, M, "International Liquidity: A Welfare Analysis," Quarterly Journal of Economics, February 1983, 98, 1-23.

Kamien, M. I. and N. L. Schwartz, "Conjectural Variations," Canadian Journal of Economics, May 1983, 16, 191-211.

Miller, M. H. and M. Salmon, "Policy Coordination and Dynamic Games," in W. H. Buiter and R. C. Marston (eds.), International Economic Policy Coordination, Cambridge, U.K., Cambridge University Press, 1985.

Oudiz, G. and J. Sachs, "International Policy Coordination in Dynamic Macroeconomic Models," in W. H. Buiter and R. C. Marston (eds.), International Economic Policy Coordination, Cambridge, U.K., Cambridge University Press, 1985.

Perry, M. K., "Oligopoly and Consistent Conjectural Variations," Bell Journal of Economics, Spring 1982, 13, 197-205.

Phelps, E. S., "Phillips Curves, Expectations of Inflation, and Optimal Unemployment over Time," Economica, August 1967, 24, 254-281.

Rogoff, K., "Can International Monetary Policy Cooperation be Counterproductive?" Journal 
of International Economics, May 1985, 18, 199-217.

Stemp, P. J. and S. J. Turnovsky, "Optimal Monetary Policy in an Open Economy," European Economic Review, July 1987, 31, 1113-1135.

Taylor, J. B., "International Coordination in the Design of Macroeconomic Policy Rules," European Economic Review, June 1985, 28, 53-81.

Turnovsky, S. J. and "Monetary and Fiscal Policy under Perfect Foresight: A Symmetric Two-Country Analysis," Economica, May 1986, 53, 139-157.

Turnovsky, S. J. and V. d'Orey, "Monetary Policies in Interdependent Economies: A Strategic Approach," in Symposium on the Coordination of Economic Policies between Japan and the U.S., Economic Studies Quarterly, June 1986, 37, 114-133. 